\title{
Approaching the notion of place by contrast
}

\author{
Stephan Winter \\ Department of Infrastructure Engineering, University of Melbourne, Australia \\ Christian Freksa \\ Spatial Cognition Research Center SFB / TR 8, University of Bremen, Germany \\ Received: May 28, 2012; returned: July 24, 2012; revised: October 6, 2012; accepted: October 16, 2012.
}

\begin{abstract}
Place is an elusive notion in geographic information science. This paper presents an approach to capture the notion of place by contrast. This approach is developed from cognitive concepts and the language that is used to describe places. It is complementary to those of coordinate-based systems that dominate contemporary geographic information systems. Accordingly, the approach is aimed at explaining structures in verbal place descriptions and at localizing objects without committing to geometrically specified positions in space. We will demonstrate how locations can be identified by place names that are not crisply defined in terms of geometric regions. Capturing the human cognitive notion of place is considered crucial for smooth communication between human users and computer-based geographic assistance systems.
\end{abstract}

Keywords: contrast, place, location, boundary, indeterminacy, objects, environment, context

\section{Introduction}

Goodchild recently wrote about the tension, when it comes to the notion of place, between formal models needed by computers and the informal world of human discourse [19]. Place has been an elusive notion in geographic information science for this reason until recently, but now place-related research emerges because capturing the human cognitive notion of place is considered crucial for smooth communication between human users and computer-based geographic assistance systems [35 49.60 68]. In this paper we study the 
notion of place as it is used in common language for answering explicit or implied where questions, and use an approach by the principle of contrast to build bridges towards formal models.

In cognitive and communicative tasks, place functions primarily as spatial anchor. The anchor locates, and connects by location, objects and events as they occur in what-, why-, when-, or how-constructions. For example, in an expression An accident happened on Beaver Street this morning, the place on Beaver Street is anchoring an event in space, answering a hypothetical or real where question. Places are typically determined by entities in the geographic environment (objects or events) or by relations between entities in the environment rather than by externally imposed coordinates and geometric properties.

As interrelated processes, cognition and language make use of places. For example, spatial reasoning happens on qualitative spatial relationships between places [13], and everyday language refers to named and unnamed places (e.g., on Federation Square, at the road intersection) and the relationships between them (e.g., at Birrarung Marr near Federation Square). Sketches, as non-metric graphical externalizations of cognitive or verbal representations, also reflect configuration knowledge of places and their relationships. And yet, despite recent progress in neuroscience and cognitive science our knowledge about cognitive representations and reasoning is not sufficient to characterize formally the entities, relations, and operations that would enable us to build a system that reflects the computational processes of spatial representations in our mind.

Freksa and Barkowsky [14| argue, for example, that the categorization into entities and relations is task-dependent. The authors illustrate this with street networks. In navigation tasks intersections are perceived as origins or destinations (or places), and street segments connect these places; alternatively, in road maintenance tasks, streets are conceived as entities, and intersections are conceived as relations between streets. But even externalized knowledge, stored in spatial databases, is challenged by the task of representing places, for a variety of reasons such as indeterminacy, context-dependence of meanings, vernacular expressions, or just the discrepancy between the formal semantics of databases and the cognitive semantics of everyday reasoning.

In this paper we will attempt to capture the cognitive and linguistic nature of notions of places, as expressed in place names or place descriptions, by the principle of contrast. We will argue that cognition of, and communication about place in spatial environments is a matter of sufficiency. Sufficiency can be captured by contrast sets, that is, by specifying the meaning of a place in a given context by explicating the contrast to other places. People conceptualize a portion of an environment as a place if their embodied experience of this portion shows a wholeness against the background, i.e., if it has some contrasting properties to its environment or to other places. Referring to such human embodied experience, our arguments and examples will focus on geographic places, i.e., on places in our physical environment of vista, environmental, or geographic scale as defined by Montello [33|.

The paper is structured as follows. After reviewing the challenges of dealing with place in current information systems (Section 2 ) we elaborate on the contrast principle in Section 3 This principle will be identified in perception and cognition in Section 4 and in communication in Section 5 Section 6 demonstrates the identified mechanisms in data from a larger corpus of place descriptions. Section 7 concludes the paper. 


\section{Place in current information systems}

Verbal references to named or unnamed places, or more complex verbal place descriptions containing several such references linked by spatial relationships, are different from the common localization approach of geographic information systems and spatial databases. Spatial databases primarily localize spatial entities by coordinates in spatial reference systems, and attach names as parameters to these geometric entities. It is well known that many places resist attempts to be described this way due to their complex geometry or due to indeterminate boundaries [7|. Accordingly, "place" is not a category in these systems. The closest matches are conventional databases for place names, such as gazetteers, address directories, or business directories. They associate a place name with a location described by a point in a spatial reference system [22]. A point is anchoring a name (label) on a map, but is insufficient to capture the spatial extent of a place, or to reconstruct spatial relationships between places. Since these points represent extended objects with potentially complex shapes, these objects can have quite different relationships than their representative points. For example, for local reasoning the distance between two places is badly represented by the distance between their centroids, and whether I am on Federation Square cannot be deduced beyond doubt from my position and the centroid of the spatial region called Federation Square.

Challenges to integrate place into coordinate-based databases are multiple. Let us discuss ambiguity, indeterminacy, preferences, and salience.

Ambiguity The meaning of a place name can be ambiguous. For example, multiple places around the world are called Melbourne, and even Melbourne in Australia has different incarnations, such as an inner city district called Melbourne (the central business district), a city called Melbourne (consisting of several districts including the central business district), and the place colloquially referred to, sometimes also called Greater Melbourne for disambiguation-the megacity most readers may have in mind. This means the name of a place cannot be expected to serve as unique identifier. But their spatial representation by a point cannot be either. An infinite number of points can be chosen to characterize a given place $^{1}$, and the same point can be used for locating different places. To overcome certain kinds of ambiguity, conventions can be introduced. For example, to specify distances between towns or cities, their respective city halls (or general post offices) have been used as reference locations. In this paper we will demonstrate how contrast sets can be used to allow for unique interpretations of place descriptions.

Indeterminacy The spatial extent of a place can be indeterminate. Places such as the city, downtown, or Mt Everest can hardly be delineated on the basis of visible entities in the environment alone [54|. Various representation mechanisms have been suggested to cope with indeterminacy, such as fuzzy sets $[1,69 \mid$, rough sets $|6.36|$, or supervaluation $[5.29 \mid$, but none of them has been widely adopted. As a visual representation, Evans and Waters suggest a spray-can tool for the visualization of indeterminate places [11]. Recent approaches to outlining places based on point observations use kernel density estimation [20,25; 63], which per se provides arbitrary boundaries by choosing a threshold. Kernel density provides high contrast in the core and less contrast in the fringes. In the present paper we argue

\footnotetext{
${ }^{1}$ For example, the inhabited place of Melbourne, Australia, is gazetteered in the Getty Thesaurus of Geographic Names at $\left(-37^{\circ} 49^{\prime} 00^{\prime \prime}, 144^{\circ} 58^{\prime} 00^{\prime \prime}\right)$ and in geonames.org at $\left(-37^{\circ} 48^{\prime} 50^{\prime \prime}, 144^{\circ} 57^{\prime} 47^{\prime \prime}\right)$.
} 
that all these representation approaches may be inadequate due to the fact that they focus on the boundary rather than on the central notion of the place concept [14]. By denoting an underspecified area as a place, e.g., this is the place to be, people do not describe boundaries; they even do not describe in which ways the place is different from locations not associated with the respective place name. Shape and extent of a place can vary dynamically, typically by means of activities: when many people attend a festival or other event that "takes place" at a given place, this place may be conceived of as larger than if small or no activities are associated with it. Boundaries may or may not be imposed implicitly through associated entities or events that may be connoted through the context. We will demonstrate how contrast sets allow us to specify a level of distinction, or to use concepts of place without being specific about boundaries.

Preferences The meaning of place names also can be stretched intentionally by individuals. For example, real estate agents sometimes stretch the extent of a more expensive suburb to justify the asking price for a house nearby, a phenomenon called vanity addressing. Also, somebody may say I am in Bremen although they are actually nearby, just because this is more informative or meaningful and sufficiently correct or precise in a particular context. The prominence of Bremen dominates over other places nearby [67|. Individuals can also use place names not recorded in databases (vernacular). If knowledge of this name is not shared in a given communication context a negotiation by dialog can be used to relate this place name to known place names [43 68|. In this paper we will demonstrate how sufficiency and dialog are natural extensions of contrast.

Salience Places contrast to their environments in different ways. Perceived as being distinguished in their standing, places get assigned asymmetric relationships, which can distort cognitive representations $[9,23,45]$. The asymmetric relationships define cognitive dependency hierarchies that are reflected in linguistic expression: in particular they can reduce the number of features to be dealt with simultaneously in a communication process, as answers to where questions have a hierarchical structure [51|. Salience itself is a property defined by contrast, and hence, contrast will be helpful to capture the salience of places.

In the discussion so far no particular need arose for identifying exact boundaries of places, although in spatial databases boundaries (polygons) are the first-order citizens of geometric representations. As a preview of the following sections, Table 1 shows a comparison between the classical geometric representations of features in spatial databases, and representations of places in place descriptions as will be elaborated in the following sections.

\section{On contrast}

Contrast is a fundamental principle in sensing and understanding. It is already embedded in the response functions of neurons, which enhance response in the presence of stimulus contrast, such that stimulus contrast is correlated with stimulus saliency. Neuroscience states that human perception treats the cognition of what (identification of a stimulus) separately from the cognition of where (localization of a stimulus) [18 32 50|. Also, psychophysi-

www.josis.org 


\begin{tabular}{|l|l|}
\hline Geometric representation & Place representation \\
\hline \hline bound to fixed scale (level of detail) & bound to a level of distinction \\
\hline $\begin{array}{l}\text { drawing boundaries (partitioning the spatial } \\
\text { domain) }\end{array}$ & $\begin{array}{l}\text { identifying anchor objects and their relations } \\
\text { (leaving unspecified what is in between) }\end{array}$ \\
\hline context-independent geometric entities & objects chosen as context suggests \\
\hline $\begin{array}{l}\text { value by accuracy (communicate complete de- } \\
\text { scriptions) }\end{array}$ & $\begin{array}{l}\text { value by relevance (communicate what needs } \\
\text { to be communicated) }\end{array}$ \\
\hline absolute interpretation & interpretation by contrast to others \\
\hline boundaries essential & boundaries irrelevant \\
\hline
\end{tabular}

Table 1: Comparing geometric representations of entities in databases and representations in place descriptions.

cal studies are made to determine thresholds where participants detect differences between stimuli [16]. A threshold is the amount of intensity change at which a participant can just detect the difference between two stimuli. Stimuli with intensity differences below the threshold are considered indistinguishable. This means there is some robustness in human judgment of equality or identity. Judgments are safer and quicker in the presence of large differences (i.e., strong contrast), and more difficult if the differences are small. For example, we are quick to identify the few landmark buildings on a campus that clearly stand out from the rest. But we have to make a number of these judgments, depending on the complexity of the differences above liminal thresholds, when we search for, say, a particular apartment building among many similar ones.

Contrast is also a prominent principle in Gestalt theory, where visual contrast was observed as one of the organizing principles of perception [31.53|. Contrast and good continuation separate foreground and background. Contrast was recently used to define salient features [41]. Salience impacts on cognitive spatial representations, for example in anchor point theory [9] or in explanations of landmarks [12 27 39]. In cognition, concepts are typically introduced through contrasting features, implicitly establishing contrasts that are used for their interpretation [14].

In language contrast is used primarily for explanations, to explain a term by examples and counterexamples [65|, or by the term and its opposites [15]. Already Aristotle applied the contrast principle in his method of division, by dividing a concept (a genus) into sub-concepts by differentiae [3|. Tenbrink and Freksa used contrast to study spatial and temporal expressions [59|, work that had been preceded by an experiment to select a place based on the contrast created by projective relationship terms [58].

Contrast focuses on the core instead of the fringes of concepts, and thus is not aiming at defining boundaries. For example, when explaining the difference between a mountain and a valley, one will succeed more easily using characteristics from the top of the mountain and the bottom of the valley then from the transition between mountain and valley. Without an instantaneous agreement on the precise meaning of a term we learn to use concepts through examples and counterexamples. The meaning of the concept evolves, and is refined when necessary. Without prior agreement on the meaning, concepts are also adaptive to changing contexts. For example, if I put my towel on the beach to mark my place, I do not specify how large my place is [21|. In fact, it will vary in the course of the day: if I am the only person on the beach, a stranger who puts his towel five meters next to mine would be considered an intruder into my place; in the afternoon, when the beach 
gets crowded, someone five meters away may not even be a neighbor. Similarly, I am on Federation Square is a safe and quick judgment when I am somewhere in the center of the square, but the judgment is becoming more difficult and ambiguous the closer I get to the periphery and other places.

These observations are our starting point to explore the contrast principle for a better understanding of place.

\section{Contrast in the perception and cognition of places}

In this section we focus on place in cognitive representations and processes. As these representations and processes are not directly accessible for the researcher, the examples in this section are taken from language, as one form of externalization of what is on our minds. The next section will study the contrast principle in linguistic expressions.

\subsection{Place: A cognitive unit}

Couclelis and Gale [8| define places as the units of (human) cognitive space, distinguishing cognitive from other spaces by group properties. For units (discrete entities) boundaries of a place do not matter, because separation from the next unit is already done by identity. Separation, or neighborhood, is a topological feature, one that is preserved even when boundaries would be shifted. Conceptual units can exist on various levels of granularity simultaneously and may correspond to nested geometrical spaces. This does not imply, however, that the coarser concepts are built up from the finer concepts.

Spatial cognition research uses physiological and behavioral parameters or externalization mechanisms such as sketching or surveying |9.10.30|. Externalization by language and sketching are particularly suited for the exploration of human concepts of place.

\subsection{Place in cognition}

Based upon an experiment to externalize cognitive concepts by sketches, Lynch has identified five elements used to represent the city [30|. These elements are paths ("channels along which the observer customarily, occasionally or potentially moves," p. 47); edges ("linear elements not considered as paths by the observer," p. 47); districts ("medium-to-large sections of the city ... which the observer mentally enters," p. 47); nodes ("strategic spots in a city into which an observer can enter, and which are the intensive foci to and from which he is travelling," p. 47); and landmarks ("the observer does not enter them, they are external ...usually a rather simply defined physical object," p. 48). Each instance of these elements is an aggregated or complex location in the city environment. This means that the instances of these elements must also have a perceivable Gestalt (a whole) that contrasts to the environment. The mind may treat them as nodes of a graph, with relationships between each other, or may refine to more elaborate recalls when needed. Each of these elements can also have some salience, or serve as a point of reference in human communication [39]. Table 2 lists these elements classified by accessibility and conceptual dimensions.

While Lynch identified these elements from studying sketch maps, these elements also occur as anchors in verbal place descriptions, together with spatial prepositions to characterize a place, such as in on Beaver Street (path), across the Weser river (edge), in Carlton

www.josis.org 


\begin{tabular}{|l|l|l|}
\hline Lynch's elements & accessible & inaccessible \\
\hline \hline OD & node & landmark \\
1D & path & edge \\
2D & district & - \\
\hline
\end{tabular}

Table 2: Categorizing Lynch's elements by accessibility and conceptual dimensions.

(district), on Federation Square (node), or in front of the Eureka Tower (landmark). Note how in these examples the distinction is constructed by a default context. Changing the context can also change the categorization of the feature in the environment. For example, if the rowing competition this afternoon will take place on the Weser river, the river in this context is a path and no longer an edge. Similarly, thinking (or talking) about [my apartment] in the Eureka Tower considers the Eureka Tower as a node that can be entered. It is no longer a landmark, in this context.

In this respect places are where one may locate objects or events. In addition, the accessibility property of instances of these elements becomes important for the definition of place. We expect that a place is accessible in some context, or even, that it affords to be accessed |17|. If it is accessible it serves as a surface ("on") or a container ("in") |26|. This affordance has been used to characterize place before. For example, Kuhn understands geographical space as a system of entities and actions [28|, and Scheider and Kuhn form a theory of networks by media that support movements, and connectedness of such media [47|. More recently, places have been characterized as media of containment [46]. A location that exerts this affordance in contrast to its environment is recognized as a whole entity, and becomes a place: a place, since it contrasts from its environment, always forms a container $|4|$.

Aristotle, who has studied aspects of place in several works (see |34| for a review), has listed signifiers of where as one out of ten universal categories of significations [2]. Thus, Aristotle defines place in contrast to the nine other categories of substance, quantity, qualification, a relative, when, pose, having, doing, or being-affected. Place and pose are the two categories that are covering significations in the spatial domain, one about the location, the other one about the orientation of an object. Beyond being named a universal category Aristotle leaves unspecified ways how place can signify the where. The generic category allows for a multiplicity of instantiations of location. For example, place can locate the signified in relationship (or contrast) to other places [58|, but place can also signify a where by a relation to space rather than the environment, typically by attaching coordinates to it such as in spatial databases.

When Tuan titled his book Space and Place [61| he not only saw this dichotomy, he also used the approach of explaining the category of place by contrast, here namely in contrast to space. According to Tuan, space is characterized by openness, either infinite or bounded (p. 4), in contrast to place which is characterized as centers, or locations where something takes place. As centers of perceived value places provide stability and permanence, while the openness of space affords to move (p. 29, p. 139). To identify and separate places from each other we expect places to have a Gestalt, or contrast to their environment. Gestalt with these characteristics makes place a coherent portion of space which satisfies the image schemata of container or surface $|26|$.

According to Tuan, distance, a concept within space, is meaningless without an idea of goal or place ([61], p. 136). Pylyshyn ([40|, p. 63) goes further and argues that attention 
selects objects, and moving the attention between objects may not be continuous but it can cross empty regions. He speaks of locations as index to the empty (open) space, and place as the location of objects in this space.

With its defining affordance characteristics and contrast to its environment, place is perceived as the union of contiguous locations over which some properties are sufficiently stable. Furthermore, places (as locations of objects) are relevant (in any particular context) only in a cognitively manageable number. A place is identified in relation to other (relevant) places. This implies that a place $P$, with a relative reference system $X$, can be specified by contrast ( $P$ against $X \backslash P$ ), while a location cannot be specified by contrast, due to the infinite number of alternatives in a continuous space. Boundaries are a concept in space, necessary to partition the infinity of locations into discrete entities in space that can be compared. In spatial databases, boundaries are constructed by positions of nodes, and linear interpolations between the nodes. We will argue, however, that boundaries are not necessary for defining places, which come in discrete (contrast) sets of objects. As centers of value, places have periphery rather than boundaries. Accordingly, describing place by the image schema of container appears a better alternative than describing place by location in space.

While a partition creates entities covering each point in space, not every point in space is necessarily in a place in some given context (but may be if we change focus). So what is place in contrast to no place? This rather phenomenological distinction found large interest in the literature. In particular, Relph's placelessness comes to mind, a location with no sense of place, or no authenticity, or no decided inside/ outside [42]. Relph observed an assimilation (loss of contrast) of places caused by mass communication and globalization. However, we may also state that some location can become a place once we are aware of it, talk about it, and thus create a mental concept.

So far, place has been identified as a center of value, and an object of identity that can be distinguished from other places. If space is not completely filled with places, people can be at locations or move between places without being able to refer to their locations as a place (I am [somewhere] between Melbourne and Sydney, or I am on my way home). However, indeterminate (unbounded) locations can form a place. For example, a larger area in the middle of Piazza San Marco may form a place because it has some wholeness or identity about it or because of some event "taking place" here. The identity inherited from the event has some contrast to other places on the piazza where this event did not happen. Places do not have to have a name, but those without may be weaker in terms of contrast. In summary, contrast helps to differentiate places from other places. Contrast can be defined as an ecological principle.

\subsection{Contrast by salience}

In general we define the existence of place by affordance. However, we also expect places, or the objects being located there and forming a place, to have some cognitive salience: some properties that can be distinguished from properties of other places. Their salience makes them preferred references in place descriptions, and thus possibly also in cognitive representations. For this discussion we go back to recent work on the nature and identification of landmarks.

The term is used here in a broader sense than by Lynch: landmarks are features in an environment that stand out by some properties "that make them recognizable and memorable

www.josis.org 
in the environment" |55|. They serve as reference points in cognitive representations of the environment [39 45|. Sorrows and Hirtle list among the characteristics that contribute to the salience of an object its singularity, its prominence, accessibility, meaning or cultural significance, and prototypicality. By these characteristics they distinguish landmarks that are salient because of visual, cognitive (meaning), or structural properties. Their classification has been widely adopted to formulate measures of salience (e.g., [41]). Place names, referring to objects located in the environment, can inherit this salience. Places of more salient objects (landmarks) have also well-known names.

Each of these characteristics can be formulated by contrast: singularity, for example, as sharp contrast to other things. The prototypical landmark is a solitaire in an environment. For example, the church in the village is the only building in the village that is a church (the contrast set being all other buildings in the village). In general, standing out means being distinguished in quantity or quality to an amount that makes a significant difference. Schelling's focal points have this contrast quality when studying representations of environments: they are not necessarily solitaires, but to some degree standing out for visual, cognitive or structural characteristics [48|.

Among all streets in Carlton, Melbourne, a few are better known. Lygon Street stands out as a center for restaurants and cafés, which has made it an attraction for locals and tourists alike. Thus, Lygon Street stands out from its environment visually and cognitively. Because it is salient, the place Lygon Street is used as point of reference in place descriptions (e.g., Tyne Street is going off Lygon Street), and in all probability, in cognitive representations as well.

\section{The contrast principle in the communication of places}

In this section we concentrate on place in linguistic expressions, and the way contrast helps to interpret a particular place description.

In linguistics, contrast is a principle of description based on complementary opposites (which is stronger than only establishing an order). Contrasting expressions allow us to differentiate and thereby help us to make judgments; they also help us to explain these judgments. It is this linguistic contrast that we will investigate further and explore in detail, following an approach already applied by Tenbrink and Freksa to study spatial terms [59|. Linguistic contrast can only take advantage of contrasts that are also cognitive, and cognitive contrasts rely on perceptual or experiential ones, hence there is a correlation between the two.

\subsection{Place as answers to where questions}

Van Fraassen ([64|, supported by [57|) identified a contrast principle in answers to why questions, i.e., answers to Why $P$, rather than $Q$, where $Q$ forms the contrast set to $P$ - the set of all alternatives to $P$ relevant to the fact in question. In this section we will argue in analogy that places, as answers to where questions, can be captured in their meaning in a particular discourse by explanations Here, rather than there, and that the meaning of here depends on the places implicitly or explicitly set out to contrast with. For example, the question Where is the movie shown? answered by The Astoria implies that it is not shown in 
any other cinema in the city, assuming that the cinemas of the city are the relevant places in this discourse.

According to van Fraassen, a why question consists of a relevance relation $R$, a domain $X$ consisting of facts $P$ and $Q$, such that $P$ can be explained from $Q$ by reasons $A$. Hence, Van Fraassen suggests that in order to evaluate an answer as an explanation of facts $P$ one needs to know the contrast class $Q$ for $P$. The contrast class consists of the set $X \backslash P$ of possible facts that did not occur (in the particular context). The explanation of $P$ must (also) answer why the alternatives did not occur: ( $P$ is true because of $A$ ) implies $(Q=X \backslash P$ is not true because of $A$ ). Furthermore, for reasons $A$ to have any explanatory power, an explanation must choose relevant reasons $A$ according to a relevance relation $R$. Reasons $A$ are considered to be true independently.

In order to construct an analogy for where questions one may give up reasons $A$. Answers to where questions do not give reasons. But answers preserve a relevance relation $R$, which comes with the discourse context of the where question and supports the choice of a domain, a set of places $X$. For example, in the context of where a movie is shown tonight the domain $X$ may consist of the cinemas of the city, but in the context of which buildings in the street need renovation The Astoria would have been taken from a different domain $X$. Thus, given a where question $W=\langle Z, R\rangle$, with $Z=\bigcup\left\{X_{i}\right\}$ being the total set of all places in the universe, $R$ would select all places relevant to the fact in question, forming the domain $X$ as a subset of all places. An answer to $W$ would look like:

\section{$P$ in contrast to $X \backslash P$ where $X \backslash P$ is relevant in the given context.}

Relevance theory was introduced by Sperber and Wilson [56].

The relevance relation $R$ typically can be concluded from the context of a discourse. For example, turning to a mobile map to locate where I am, the place Federation Square (Figure 1) appears to be a member of a set of connected places at the banks of the Yarra River, $X=\{$ Federation Square, Flinders Street Station, Birrarung Marr $\}$. Thus deciding that $I$ am on Federation Square means that I exclude being in Flinders Street Station or on Birrarung Marr: $X \backslash P=$ FFlinders Street Station, Birrarung Marr $\}$ in this context. This contrast set provides a particular interpretation of the spatial realization of the notion of Federation Square, without being specific about Federation Square's boundaries.

But now let us switch the discourse. Federation Square, in another context, is a member of the set of (dispersed) event locations in Melbourne, $X=\{$ Federation Square, Botanical Garden, Town Hall $\}$. Thus, The play is shown on Federation Square implies in this context: don't go to the Town Hall or the Botanical Garden to watch it. This contrast set provides another particular interpretation of the spatial realization of the notion of Federation Square. For example, with the blurry transition from Federations Square to Birrarung Marr in a complex built environment, and the dominant salience of Federation Square in its local neighborhood, a vanity use of the place name Federation Square would be acceptable: the play could be shown, for example, on the large stairs down from Federation Square to Birrarung Marr on the embankment of the Yarra River, a place that would not be accepted as a valid interpretation in the first context.

In the context of the first example, the stairs between Federation Square and Birrarung Marr help us to identify another interesting observation. Assume that somebody wants to arrange a meeting with a friend, and started the dialog with a domain of places $X=\{$ Federation Square, Flinders Street Station, Birrarung Marr $\}$ in mind. But the play will take place on the stairs between Federation Square and Birrarung Marr such that a 


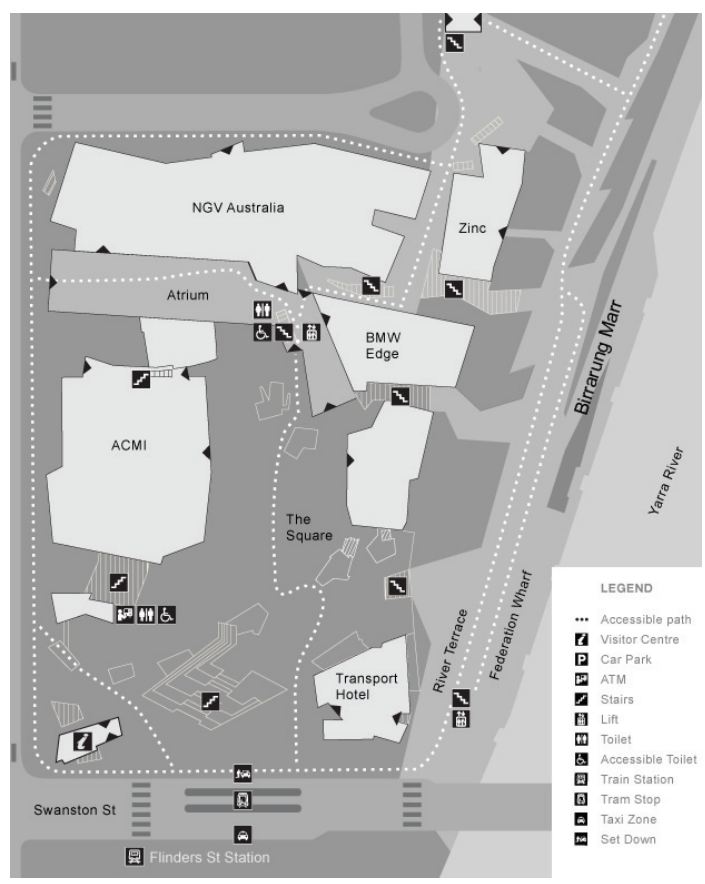

Figure 1: Federation Square (map from fedsquare.com, modified).

statement Come to Federation Square would be ambiguous. In order to arrange for a meeting successfully the speaker does not insist on her subjective judgment whether the intended meeting place is still on Federation Square or already on Birrarung Marr [7]. Instead she would switch granularity. The new domain is $X^{\prime}=\{$ The Square, Zinc, BMW Edge, River Terrace, Federation Wharf\}: places located in the area between Federation Square and Biarrung Marr. As the first place description Come to Federation Square was not specific enough it is now further specified by zooming in: on Federation Square, the River Terrace. In this case Federation Square may have been chosen and not Birrarung Marr because of its dominant salience. The conversation does not state that the play is on Federation Square but not on Birrarung Marr; it rather avoids making this decision.

The contrast classes are not explicit in many explanations of where. Generally $X$ can have gaps in the presence of disagreement about the domain (compare, e.g., $X=$ $\{$ Federation Square, Flinders Street Station, Birrarung Marr $\}$ with $X^{\prime \prime}=\{$ Federation Square, Flinders Street Station, Birrarung Marr, St Paul's $\}$; both are serving the first example sufficiently well. Completeness, as much as it might be desired in some contexts, seems to be not required in the communication process. Even more, instead of an extensional list of alternatives $X$ can also be taken intensionally. In the dialog: Which suburb? ... Carlton, the implicit alternatives (in this case finite and known) are all the other suburbs of Melbourne.

\subsection{Types of where questions}

Where questions come in different flavors, revealing different uses of the contrast principle. 


\subsubsection{Identifying the domain}

The domain $X$, or the contrast set $X \backslash P$ respectively, depend on the discourse context. For example, in order to explain where I am I might say I am on Federation Square. However, the sentence can have different meanings in different communication contexts. Accordingly, a relevance function would determine different categories as the domain $X$ (or the contrast set $X \backslash P)$. As we have seen above, if the communication is about negotiating a meeting point for a recipient nearby then the contrast set consists of other places nearby to avoid missing each other (I am on Federation Square, not in Birrarung Marr, Flinders Street Station, or Swanston St). Alternatively, if the context is about negotiating a meeting with a partner who is about to leave the hotel the contrast set are the touristic spots to be visited that day (I am on Federation Square, not in the town hall, Eureka Tower, or Immigration Museum). If the domain has not become clear in the course of the communication the longer explanations may provide the necessary context information.

Thus, a discourse can be used to disambiguate an explanation. In I am in the train station the speaker might have expected this place description to be unambiguous in the given context (the train station, not the office or home), but a question Which one? will request a change of the domain ( $X=\{$ Flinders Street Station, Southern Cross Station, Melbourne Central Station\}) for a further disambiguation.

\subsubsection{Choosing a level of spatial granularity}

Place descriptions are known to have a structure that either zooms in by spatial granularity, or zooms out |37.38|. Take the example of postal addresses, even if it is not a typical common language description: 20 King Street, Melbourne zooms out from a building identifier, to a street, to a suburb. Similarly, the office is in the city hall, second floor is zooming in. Thus, the notion of place allows for nesting. Jolimont Espresso is a place in the Atrium, which is a place on Federation Square. Federation Square is a place in Melbourne.

In line with Aristotle's Physics [4], every object has its own proper location, defined by its spatial embedding. This location belongs to several places by different abstraction mechanisms. For example, one piece of land belongs to a city district, to a commune, to a state, and to a country; each of the belongings is regulated by some abstract rules. Thus, the building on this piece of land is at the same time on this land, in this city district, in this city, and in this country.

The abstraction of location to places does abstract from boundaries, and hence, places at a certain level of granularity do not form partitions of space while locations might do (e.g., [40|). But since we recognize and memorize places at different levels of granularity, places at one level of granularity can belong to places at coarser levels of granularity. Thus, places can be ordered by lattices of spatial granularity (we assume lattices rather than hierarchies because there may be multiple superset-subset relationships). For example, Richter et al. [44 | distinguished a functional, a social, and a physical hierarchy for indoor environments. Similarly administrative partitions can form hierarchies, and different hierarchies lead to lattices of places of spatial granularity. The classical example are postal addresses where postcode districts do not necessarily coincide with political boundaries. In each of these lattices the elements of one level of granularity form a domain $X$. For example, the piece of land is 120 Lygon Street (and not 118 or 122), it is in Carlton (not Parkville and not Fitzroy), and it is in postcode area 3053, not 3051.

www.josis.org 
Granularity implies a certain degree of abstraction. Characteristics relevant at a finer level of granularity are neglected [24]. This means places at a particular level of granularity are not completely specified. Siegel and White, for example, acknowledge a difference between seeing a place, based on exterior form, and memorizing, which is based on an abstraction or a symbol ([52], p. 16). An apartment in Carlton is less specific in terms of granularity than an apartment on Lygon Street in Carlton.

Context determines, via a relevance function $R$, the choice of the conceptual hierarchy (e.g., a functional, social or physical one) and of the level of granularity within the chosen hierarchy. An example for the latter was given above, where uncertainty about a location between Federation Square and Birrarung Marr induces to move to a finer level of granularity. Both selection processes are essential for the contrast principle, since it would be too time-consuming to make large numbers of comparisons among $P$ and $Z$. Hierarchies and a relevance function break down the number of required comparisons to a short list, $P$ against $X \backslash P$.

Prior work has illustrated already how a relevance function can be formally specified to derive a relevant domain $X$. Tomko and Winter have generated travel destination descriptions relevant for the start and destination location in question [60], and vice versa, $\mathrm{Wu}$ and Winter have taken these rules into consideration to understand human destination descriptions [68|. In both approaches the major context factors were (a) the purposecommunicating a destination of a travel - and (b) the current locations of the speaker, the recipient, and the destination itself. The former, which was fixed, determined appropriate domains $X$, and the latter enabled a relevance function to determine appropriate levels of granularity. In order to design generic relevance functions it needs an automatic recognition of the purpose of the communication.

\section{Case study: Federation Square in place descriptions}

We will demonstrate the principles identified above by a case using human place descriptions of Federation Square in Melbourne. As a public square and center for cultural life, Federation Square is already a prototypical place according to our definitions above. But how is contrast used to explain the notion of this place? Two kinds of descriptions are considered. One is the kind that may be found in travel guides (here taken from Wikipedia). The other is the kind that would be given as a response to "Tell me where you are." For the latter, we considered all 26 place descriptions relating to Federation Square from a corpus of 2221 place descriptions that were collected in the context of a mobile location-based game [66].

Wikipedia ${ }^{2}$, similar in style and content to any travel guide, characterizes Federation Square as follows: "Federation Square (also colloquially known as Fed Square) is a cultural precinct [...]. In addition to a number of shops, bars, cafés, and restaurants, Federation Square's cultural facilities include:", and here follows a list of attractions such as two museums (the Australian Centre for the Moving Image and the National Gallery of Victoria), a theater and an event center, a public radio broadcaster, three major public spaces, and a large public screen. It appears that Federation Square is primarily functioning as an event precinct, and hence its affordance is primarily to stay: a destination rather than an environment to travel through, and somehow standing out in the urban environment. Fur-

\footnotetext{
${ }^{2}$ Last accessed 21 May 2012.
} 
thermore, its location is described as: "Federation Square occupies roughly a whole urban block bounded by Swanston, Flinders, and Russell Streets and the Yarra River. The open public square is directly opposite Flinders Street Station and St Paul's Cathedral." Here we find places that contrast locally to Federation Square (Federation Square in contrast to Swanston St, etc.). Both function and location indicate levels of spatial granularity by referring either to places that belong to Federation Square, or to places that contrast locally to Federation Square. Both descriptions have to be relevant, i.e., the levels of granularity have to be found appropriate for the given purpose.

Telling us where they are, we have collected 26 place descriptions made on Federation Square or next to it. Since the place descriptions were collected through a mobile phone application the original spelling is preserved here and multiple responses are indicated. The data collection was anonymous. Of the 26 descriptions, 23 use the place name Federation Square, and three of them the colloquial Fed Square.

The following place descriptions were given:

1. "federation square" (11 occurrences), "fed square" (2), "i am at federation square" (2), "I am at fed square", "On federation square"

2. "overlooking federation square"

3. "In front of flinders street station, opposite of federation square"

4. "North-west corner of Federation Square, opposite Flinders St Station."

5. "At the entrance of federation square, still downstairs (at the visitor centre)"

6. "At the ACMI, entrance on federation square"

7. "In Bok Choi, the Chinese restaurant at federation square - top floor"

8. "federation square, cnr flinders street and swanston street"

9. "federation square corner st kilda road and flinders street, melbourne vic 3000"

10. "at federation square, on the eastern side of st kilda road opposite flinders street station in melbourne city."

In these descriptions, the discourse domain implied by the speakers seems to change; the mobile game was unspecific about a context. Thus, (1), the most popular type of place description, trusts completely the global prominence of Federation Square, or results from the laziness of players coming up with minimal versions of place descriptions; (2), with the activity of overlooking, says something about the spatial granularity of the place, as well as about a Gestalt; (3) is technically not on Federation Square, but is an example of contrasting with nearby places; (4) is more specific on the location, i.e., moves to a finer level of granularity implying a context in which "on Federation Square" alone is not sufficient; (5), (6), and (7) do the same, but use other places at the finer level of granularity, i.e., the speakers are at different locations on Federation Square; (8) and (9) zoom out, referring to places of larger extent (paths and a district) nearby and contrasting with; (10) shows a mixed form: it has the contrast with other places nearby (a station and a street), but also the zoom out by referring to a larger place (district).

\section{Conclusions}

In this paper we have approached the notion of place as used in cognition and language. Means of this approach was the contrast principle, for both, cognition and language.

Even if it is not yet completely understood how human spatial cognition works, all the evidence from neuroscience and cognitive science suggests that these processes do not 
work on a coordinate-based geometry. The term cognitive map has been identified to be rather a metaphor (e.g., |62| for cognitive structures and processes). Instead, spatial cognitive representations seem to rely on places as entities. If spatial reasoning processes are based on places and their relations then understanding places is a first step towards understanding spatial cognition. We have argued that places are used through identity in discourse domains, instead of vector representations. Hence, talking about place-answering where questions-happens through implicit or explicit contrast to other places. Such a mechanism avoids a commitment to boundaries, and instead prefers to refine the level of granularity where necessary. This means, the contrast principle is about efficiency in communication, requiring from the communication partners only to be as specific as necessary. What is necessary in a given context is defined individually by a relevance function.

Place has been defined as an accessible surface or container. Also locations that expose node, path, or district properties within a context form places. Additionally, change of context can change the nature of the location. Furthermore, place has been characterized by affordance and by salience. Salience in itself is a principle relying on contrast, which helps to understand the category of place. But contrast exists also between salient entities, i.e., helps understanding the instances of the category. Thus, contrast has an explanatory power, where the contrast set is dependent on the domain of discourse via a relevance relation. Using the contrast principle to explain places has been shown to be independent from coordinate geometry. Instead, where an explanation at a certain level of granularity (abstraction) has been found underspecified a refinement process has been observed. Refinements are made to a level of sufficient specifications for a given context, according to the relevance relation. However, in none of the examples it has been necessary to relate to boundaries or coordinates.

In this paper we have focused on places of vista, environmental, and geographic scale as places of interest. The arguments and examples, however, might also hold on other scales. Future work should attempt to generalize this investigation to places of other scales, such as table-top or smaller.

Since our technical systems in geographic information science are based on vector or raster geometry, their entities, relations, and operations are different from cognitive systems. If we want to support the cognitive concept of place it will be interesting to study further what relations and operations are needed to be able to generate appropriate information from querying a geographic information system. This question is challenging when we consider also the context-dependency between cognitive and geographic objects [14|.

\section{Acknowledgments}

Generous support to the Spatial Cognition Research Center SFB/TR 8 from the German Research Foundation is gratefully acknowledged. The work was also supported by the Australian Research Council under its Linkage Program (LP100200199), and by travel support from a grant under the Go8/DAAD exchange schema. The comments of anonymous reviewers have helped to improve the clarity of the arguments.

\section{References}

[1] Altman, D. Fuzzy set theoretic approaches for handling imprecision in spatial 
analysis. International Journal of Geographical Information Systems 8, 3 (1994), 271-289. doi:10.1080/02693799408902000

[2] ARistotle. Categories. In The complete works of Aristotle, J. Barnes, Ed. Princeton University Press, Princeton, 1995, pp. 3-24.

[3] ARistotle. Metaphysics. eBooks@Adelaide. The University of Adelaide Library, Adelaide, SA, 2007.

[4] Aristotle. Physics. eBooksAdelaide. The University of Adelaide Library, Adelaide, South Australia, 350BC. Translated by R. P. Hardie and R. K. Gaye.

[5] BennetT, B. Application of supervaluation semantics to vaguely defined spatial concepts. In Spatial information theory, D. R. Montello, Ed., vol. 2205 of Lecture Notes in Computer Science. Springer, Berlin, 2001, pp. 108-123. doi:10.1007/3-540-45424-1_8.

[6] Bittner, T., And Stell, J. Vagueness and rough location. GeoInformatica 6, 2 (2002), 99-121. doi:10.1023/ A:1015291525685

[7] Burrough, P. A., AND Frank, A. U., Eds. Geographic objects with indeterminate boundaries, vol. 2 of ESF-GISDATA. Taylor \& Francis, 1996.

[8] Couclelis, H., AND Gale, N. Space and spaces. Geografiska Annaler B 68, 1 (1986), $1-12$.

[9] Couclelis, H., Golledge, R. G., Gale, N., And Tobler, W. Exploring the anchorpoint hypothesis of spatial cognition. Journal of Environmental Psychology 7 (1987), 99-122. doi:10.1016/S0272-4944(87)80020-8

[10] Downs, R. M., And Stea, D. Image and environment. Aldine Publishing Company, Chicago, 1973.

[11] Evans, A., AND WATERs, T. Mapping vernacular geography: Web-based GIS tools for capturing 'fuzzy' or 'vague' entities. International Journal of Technology, Policy and Management 7, 2 (2007), 134-150. doi:10.1504/IJTPM.2007.014547.

[12] Evans, G. W., Brennan, P. L., Skorpanich, M. A., And Held, D. Cognitive mapping and elderly adults: Verbal and location memory for urban landmarks. Journal of Georontology 39, 4 (1984), 452-457. doi:10.1093/geronj/39.4.452

[13] FREKSA, C. Qualitative spatial reasoning. In Cognitive and linguistic aspects of geographic space, D. M. Mark and A. U. Frank, Eds., NATO ASI Series D: Behavioural and Social Sciences. Kluwer Academic Press, Dordrecht, The Netherlands, 1991, pp. 361-372.

[14] FREKSA, C., AND BARKOWSKY, T. On the relations between spatial concepts and geographical objects. In Geographic objects with indeterminate boundaries, P. A. Burrough and A. U. Frank, Eds., vol. 2 of GISDATA. Taylor \& Francis, 1996, pp. 109-121.

[15] FREUD, S. Über den Gegensinn der Urworte. Jahrbuch der psychoanalytischen und psychopathischen Forschung 2, 1 (1910), 179-184.

[16] Gescheider, G. A. Psychophysics: The fundamentals, 3rd ed. ed. L. Erlbaum Associates, Mahwah, N.J ., 1997.

www.josis.org 
[17] GiBson, J. The ecological approach to visual perception. Erlbaum, Hillsdale, NJ, 1979.

[18] Goodale, M. A., AND Milner, D. Separate visual pathways for perception and action. Trends in Neurosciences 15, 1 (1992), 20-25. doi:10.1016/0166-2236(92)90344-8

[19] GoodchilD, M. F. Formalizing place in geographical information systems. In Communities, neighborhoods, and health: Expanding the boundaries of place, L. M. Burton, S. P. Kemp, M.-C. Leung, S. A. Matthews, and D. T. Takeuchi, Eds. Springer, New York, 2011, pp. 21-35. doi:10.1007/978-1-4419-7482-22.

[20] GROTHE, C., AND SCHAAB, J. Automated footprint generation from geotags with kernel density estimation and support vector machines. Spatial Cognition and Computation 9, 3 (2009), 195-211. doi:10.1080/13875860903118307

[21] Hall, E. T. The hidden dimension. Doubleday \& Company, Garden City, NY, 1966. doi:10.1177/001316446602600462

[22] HILl, L. L. Georeferencing: The geographic associations of information. Digital Libraries and Electronic Publishing. The MIT Press, Cambridge, MA, 2006. doi:10.5062/F4416V09

[23] Hirtle, S. C., AND Jonides, J. Evidence of hierarchies in cognitive maps. Memory and Cognition 13, 3 (1985), 208-217. doi:10.3758/BF03197683

[24] HоввS, J. R. Granularity. In Proc. 9th International Joint Conference on Artificial Intelligence (Los Angeles, CA, 1985), A. K. Joshi, Ed., Morgan Kaufmann, pp. 432-435. doi:10.1.1.74.7822

[25] Hollenstein, L., AND PuRVes, R. Exploring place through user-generated content: Using Flickr to describe city cores. Journal of Spatial Information Science 1, 1 (2010), 21-48. doi:10.5311/ JOSIS.2010.1.3

[26] Johnson, M. The body in the mind: The bodily basis of meaning, imagination, and reason. The University of Chicago Press, Chicago, 1987.

[27] KlipPeL, A., AND Winter, S. Structural salience of landmarks for route directions. In Spatial information theory, A. G. Cohn and D. M. Mark, Eds., vol. 3693 of Lecture Notes in Computer Science. Springer, Berlin, 2005, pp. 347-362. doi:10.1007/11556114_22.

[28] KUHN, W. Ontologies in support of activities in geographical space. International Journal of Geographical Information Science 15, 7 (2001), 613-632.

[29] KULIK, L. A geometric theory of vague boundaries based on supervaluation. In Spatial information theory, D. R. Montello, Ed., vol. 2205 of Lecture Notes in Computer Science. Springer, Berlin, 2001, pp. 44-59. doi:10.1007/3-540-45424-1_4

[30] LYNCH, K. The image of the city. MIT Press, Cambridge, 1960.

[31] Metzger, W. Gestalt und Kontrast. Psychologische Forschung 15, 1 (1931), 374-386. doi:10.1007/BF00406048 
[32] Mishkin, M., Ungerleider, L. G., And Macko, K. A. Object vision and spatial vision: Two cortical pathways. Trends in Neurosciences 6 (1983), 414-417. doi:10.1016/0166-2236(83)90190-X

[33] Montello, D. R. Scale and multiple psychologies of space. In Spatial information theory, A. U. Frank and I. Campari, Eds., vol. 716 of Lecture Notes in Computer Science. Springer, Berlin, 1993, pp. 312-321. doi:10.1007/3-540-57207-4_21

[34] Morison, B. On location. Oxford Aristotle Studies. Clarendon Press, Oxford, 2002.

[35] Norman, D. A. Design rules based on analyses of human error. Communications of the ACM 26, 4 (1983), 254-258. doi:10.1145/360000/358092

[36] PAWLAK, Z. Rough sets. International Journal of Computer and Information Sciences 11, 5 (1982), 341-356. doi:10.1007 / BF01001956

[37] Plumert, J. M., Carswell, C., DeVet, K., And Ihrig, D. The content and organization of communication about object locations. Journal of Memory and Language 34 (1995), 477-498. doi:10.1006/jmla.1995.1022

[38] Plumert, J. M., Spalding, T. L., And Nichols-Whitehead, P. Preferences for ascending and descending hierarchical organization in spatial communication. Memory and Cognition 29, 2 (2001), 274-284. doi:10.3758/BF03194921

[39] Presson, C. C., AND Montello, D. R. Points of reference in spatial cognition: Stalking the elusive landmark. British Journal of Developmental Psychology 6 (1988), 378-381. doi:10.1111/j.2044-835X.1988.tb01113.x

[40] Pylyshyn, Z. W. Things and places: How the mind connects with the world. The Jean Nicod Lectures. The MIT Press, Cambridge, Massachusetts, 2007.

[41] Raubal, M., AND Winter, S. Enriching wayfinding instructions with local landmarks. In Geographic information science, M. J. Egenhofer and D. M. Mark, Eds., vol. 2478 of Lecture Notes in Computer Science. Springer, Berlin, 2002, pp. 243-259. doi:10.1007/3-540-45799-2_17.

[42] Relph, E. C. Place and placelessness. Pion Ltd., London, UK, 1976.

[43] Richter, K.-F., TOMKO, M., AND Winter, S. A dialog-driven process of generating route directions. Computers, Environment and Urban Systems 32, 3 (2008), 233-245. doi:10.1016/j.compenvurbsys.2008.02.002

[44] RichteR, K.-F., Winter, S., AND RÜEtschi, U.-J. Constructing hierarchical representations of indoor spaces. In Tenth International Conference in Mobile Data Management, Workshop on Indoor Spatial Awareness (Taipei, Taiwan, 2009), Y.C. Tseng, P. Scheuermann, and R. H. Güting, Eds., IEEE Press, pp. 686-691. doi:10.1109/MDM.2009.117.

[45] Sadalla, E. K., Burroughs, W. J., And Staplin, L. J. Reference points in spatial cognition. Journal of Experimental Psychology: Human Learning and Memory 6, 5 (1980), 516-528. doi:10.1037 / / 0278-7393.6.5.516. 
[46] SCheider, S., AND JANOWICZ, K. Places as media of containment. In GIScience 2010 (Zurich, Switzerland, 2010).

[47] SCHEIDER, S., AND KUHN, W. Affordance-based categorization of road network data using a grounded theory of channel networks. International Journal of Geographical Information Science 24, 8 (2010), 1249-1267. doi:10.1080/13658810903514198.

[48] Schelling, T. C. The strategy of conflict. Harvard University Press, Cambridge, Mass., 1960.

[49] SCHMID, F., AND KUnTZSCH, C. In-situ communication and labeling of places. In Proc. 6th International Symposium on LBS and TeleCartography (Nottingham, UK, 2009), M. Jackson, S. Anand, and G. Gartner, Eds.

[50] Schneider, G. E. Two visual systems. Science 163, 3870 (1969), 895-902. doi:10.1126/ science.163.3870.895

[51] ShanON, B. Answers to where-questions. Discourse Processes 6 (1983), 319-352. doi:10.1080/01638538309544571

[52] Siegel, A. W., AND White, S. H. The development of spatial representations of large-scale environments. In Advances in child development and behavior, H. W. Reese, Ed., vol. 10. Academic Press, New York, 1975, pp. 9-55.

[53] Sмith, B., Ed. Foundations of gestalt theory. Philosphia Resources Library. Philosophia Verlag, Munich, 1988.

[54] SMith, B., AND MARK, D. M. Do mountains exist? Towards an ontology of landforms. Environment and Planning B 30, 3 (2003), 411-427. doi:10.1068/b12821

[55] Sorrows, M. E., AND Hirtle, S. C. The nature of landmarks for real and electronic spaces. In Spatial information theory, C. Freksa and D. M. Mark, Eds., vol. 1661 of Lecture Notes in Computer Science. Springer, Berlin, 1999, pp. 37-50. doi:10.1007/3-540-48384-5_3.

[56] Sperber, D., And Wilson, D. Relevance: Communication and cognition. Basil Blackwell, Oxford, 1986. doi:10.1017/S004740450001318X.

[57] Temple, D. Discussion: The contrast theory of why-questions. Philosophy of Science 55, 1 (1988), 141-151.

[58] TENBRINK, T. Identifying objects on the basis of spatial contrast: An empirical study. In Spatial cognition IV: Reasoning, action, interaction, C. Freksa, M. Knauff, B. KriegBrückner, B. Nebel, and T. Barkowsky, Eds., vol. 3343 of Lecture Notes in Artificial Intelligence. Springer, Berlin, 2005, pp. 124-146. doi:10.1007/978-3-540-32255-9_8

[59] Tenbrink, T., AND FreKsa, C. Contrast sets in spatial and temporal language. Cognitive Processing 10, Supplement 2 (2009), 322-324. doi:10.1007/s10339-009-0309-4

[60] TOMKo, M., AND Winter, S. Pragmatic construction of destination descriptions for urban environments. Spatial Cognition and Computation 9, 1 (2009), 1-29. doi:10.1080/13875860802427775 
[61] TuAn, Y.-F. Space and place: The perspective of experience. University of Minnesota Press, Minneapolis, MN, 1977.

[62] TVersky, B. Cognitive maps, cognitive collages, and spatial mental models. In Spatial information theory, A. U. Frank and I. Campari, Eds., vol. 716 of Lecture Notes in Computer Science. Springer, Heidelberg, 1993, pp. 14-24. doi:10.1007/3-540-57207-42.

[63] Twaroch, F., Jones, C. B., AND AbDelmoty, A. I. Acquisition of a vernacular gazetteer from web sources. In First International Workshop on Location and the Web (Beijing, China, 2008), S. Boll, C. B. Jones, E. Kansa, P. Kishor, M. Naaman, R. Purves, A. Scharl, and E. Wilde, Eds., ACM Press, pp. 61-64. doi:10.1145/1367798.1367808

[64] VAn FraAsSen, B. C. The pragmatics of explanation. American Philosophical Quarterly 14, 2 (1977), 143-150. doi:10.1093/0198244274.003.0005

[65] Winston, P. H. Learning structural descriptions from examples. Technical Report AITR-231, MIT, 1970.

[66] Winter, S., Baldwin, T., Cavedon, L., Stirling, L., Kealy, A., Duckham, M., RAJABIfARD, A., AND Richter, K.-F. Starting to talk about place. In Proc. Surveying and Spatial Sciences Biennial Conference 2011 (Wellington, NZ, 2011), B. Hock, Ed., Surveying and Spatial Sciences Institute, pp. 63-73.

[67] Winter, S., TOMKO, M., EliAs, B., AND SEster, M. Landmark hierarchies in context. Environment and Planning B 35, 3 (2008), 381-398. doi:10.1068/b33106.

[68] WU, Y., AND WINTER, S. Interpreting destination descriptions in a cognitive way. In Workshop on Computational Models for Spatial Language Interpretation and Generation (CoSLI-2) (Boston, USA, 2011), J. Hois, R. Ross, J. Kelleher, and J. Bateman, Eds., vol. 759, CEUR-WS.org, pp. 8-15.

[69] ZADEH, L. A. Fuzzy sets. Information and Control 8 (1965), 338-353. doi:10.1016/S0019-9958(65)90241-X 